International Journal of Agriculture, Environment and Bioresearch

Vol. 5, No. 01; 2020

ISSN: $2456-8643$

\title{
PRODUCTIVITY OF IRRIGATED AND RAINFED RICE (Oryza sativa L.) AS INFLUENCED BY SEEDLING AGE AND ROW SPACING, IN KURU PLATEAU STATE NIGERIA
}

\author{
Nasamu Michael A. And Garba Ali A \\ Faculty Of Agriculture And Agricultural Technology ,Abubakar Tafawa Balewa University. Bauchi. Nigeria
}

https://doi.org/10.35410/IJAEB.2020.5461

\begin{abstract}
A Field experiment was conducted in Kuru Plateau State, Nigeria, during the dry and wet seasons of 2016, 2017 and 2018 to study the effect of seedling age and row spacing on the production of rice. A lowland variety FARO 44 was used for the trial and the treatments used consisted of four seedling ages of 15,17,19 and 35-days after the seeds were sown in the nursery with direct seeded as control, three different inter and intra row spacings of $15 \mathrm{~cm} 15 \mathrm{~cm}$, $20 \mathrm{~cm} \times 20 \mathrm{~cm}$ and $25 \mathrm{~cm} \times 25 \mathrm{~cm}$ and two seasons (wet and dry). Seedling age and the row spacings were factorially combined and laid in a randomized complete block design (RCBD) and replicated 3 times. Six separate trials were carried out, three during the dry season and three during the wet season. The results indicated that seedling age, row spacing and cropping season, had significant $(\mathrm{P} \leq 0.05)$ effect on the growth and yield characters of the crop. Transplanting 19day old seedlings produced significantly $(\mathrm{P} \leq 0.05)$ taller plants with more tillers, panicles/hill, spikelets/panicle, higher seed weight and grain yield than the other seedling ages used. Similarly, growing the crop at row spacing of $25 \times 25 \mathrm{~cm}$ produced significantly $(\mathrm{P} \leq 0.05)$ taller plants with higher number of tillers, more panicles/hill, spikelets/panicle, higher seed weight and grain yield than the other spacings used. Growing the crop during the dry season on the other hand, produced significantly $(\mathrm{P} \leq 0.05)$ higher number of tillers, seed weight and grain yield, while the wet season cropping had taller plants, heavier panicles and more spikelets/panicle. Based on the results obtained, transplanting 19-day old seedlings at a row spacing of $25 \times 25 \mathrm{~cm}$ during the dry season seemed more promising for higher rice production in the study area.
\end{abstract}

Keywords: Seedling age, Row Spacing, Transplanting, FARO 44, Kuru, Nigeria.

\section{INTRODUCTION}

In many parts of Africa including Nigeria, the major challenges facing agriculture is how to increase farm production to meet challenging food needs without degrading the natural resource base. The agricultural sector is the most important in African economy employing as much as 50 to 80 percent of the labor force (Johnson, 1961). The most critical problems in Africa today is how to increase agricultural production to meet increasing food demand arising from an increase in population pressure (Mensah, 1989; Timberlake, 1990; Pretty, 1995). Rice being a staple food crop in most countries in Africa could help solve the plethora of social challenges facing the continent. In Nigeria the demand for rice is continuously growing with per capita consumption increasing at more than $3 \%$ annually since the late 1990 s with per capita consumption put at 
$35 \mathrm{~kg} /$ person/year (USDA, 2010). At the same time Nigeria is experiencing a significant population growth rate estimated at $3.0 \%$ per annum (FAO, 2015). This increase in population growth rate also comes with intensification of urbanization, and shifting preferences towards 'premium' rice. Rice is considered an essential crop in Nigeria and is produced in most of the farming ecologies, however production has remained mostly small scale which account for $80 \%$ of total production, Nigeria is one of the largest rice producers in Africa and equally one of the largest rice importers in the world (FAO, 2017). Over the past few years rice production has increased due to renewed vigor from the part of the government through favorable policies geared towards increasing production, however productivity remain low. In order to keep this pace of growth and to increase productivity new technologies needs to be encouraged with attendant high adoption rate among the small holder farming population, such technologies include early transplanting of seedlings, sowing of single seedlings per hill as well as increase row spacing among others.

\section{MATERIALS AND METHODS}

A Field experiment was conducted during the dry and wet seasons of 2016, 2017 and 2018 at the research farm of potato program, National Root Crops Research Institute (NRCRI), Kuru Plateau State, Nigeria. The research was carried out to study the productivity of rain fed and irrigated rice as influenced by seedling age and row spacing under both dry and wet cropping seasons. Kuru is located at latitude $08^{\circ} 44 \mathrm{~N}$ and longitude $09^{\circ} 44 \mathrm{E}$. The altitude ranges from 1200 meters to a peak of 1,870 meters above sea level around Shere hills. Though situated in the tropical zone, the high altitude means that Kuru has a near temperate climate with an average temperature of between $18^{\circ} \mathrm{c}$ and $22^{\circ} \mathrm{c}$. The experimental material, variety FARO 44 was sourced from the National Agricultural Seed Council (NASC). It is a lowland variety otherwise known as Sippi 692033 and the variety was released and registered between 1990 and 1991. It is a medium maturing type, taking 110-120 days to mature, high yielding between 4 to $8 \mathrm{t} / \mathrm{ha}$, tolerant to blight and has long grains. The treatments consisted of 4 seedling transplanted ages, 15,17, 19 and 35 days after sowing in the nursery, direct seeded plots considered as control and 3 inter and intra row spacing $(15 \mathrm{~cm} \times 15 \mathrm{~cm}, 20 \mathrm{~cm} \times 20 \mathrm{~cm}$ and $25 \mathrm{~cm} \times 25 \mathrm{~cm})$. These treatments were tested in two different cropping seasons (wet and dry) within a year for three years. The 4 transplanted ages and control and the 3-row spacing gave fifteen treatment combinations which where factorially combined and laid out in Randomized Complete Block Design (RCBD) with three replications. According to SRI recommendations, seed rates of $8.5 \mathrm{~kg} / \mathrm{ha}$ and $17 \mathrm{~kg} / \mathrm{ha}$ which gave an equivalent of $163 \mathrm{gms}$ and $108.8 \mathrm{gms}$ of seeds for the transplanted and direct sown plots, respectively were used.

Before application in the nursery and for the direct sown plots, the seeds were first soaked in water for 24 hours, where floated seeds (immature) were discarded. A nursery bed measuring $1 \mathrm{mx} 10 \mathrm{~m}\left(10 \mathrm{~m}^{2}\right)$ was then prepared close to the research field so as to minimize transportation time between seedling removal from the seed bed and its transportation to the field. The pregerminated seeds were broadcasted in the nursery and covered lightly with sand and then covered again with a thin layer of mulch (using dry grass). The mulch was however, removed 3 days after. The nurseries beds were irrigated daily for both the dry and wet season experiments. The seedlings emerged 5 days after sowing the seeds in the nursery for both the dry and wet 
season nurseries. For the direct sown seeds however, it took 10 days for the seedlings to emerge on the plots. The plots were marked out in a 'grid' with square pattern at a spacing of $15 \mathrm{~cm} \mathrm{x}$ $15 \mathrm{~cm}, 20 \mathrm{~cm} \times 20 \mathrm{~cm}$ and $25 \mathrm{~cm} \times 25 \mathrm{~cm}$ inter and intra row for both the direct and transplanted plots. All the seeds were sown at the intersection of the lines. For the direct seeded plots, three seeds were sown per hill, which were later thinned to one seedling per stand after seedlings were fully established at 3 weeks after emergence. Under the dry season, sowing was carried out on 28 February 2016, 2017 and 2018, transplanting of seedlings started 15 days after sowing in the nursery corresponding to 10 days after emergence. In the same vein, under the wet season experiment, sowing was carried out on the 5 of June 2016, 2017 and 2018 and the transplanting of seedlings started 15 days after sowing in the nursery which corresponds to 10 days after emergence. During the dry and wet seasons, selective pre-emergence herbicide was applied using knapsack sprayer immediately after the seeds were sown in the nursery as well as the direct seeded plots. Thereafter, manual weeding was carried out at 6,10 and 14 weeks after sowing (WAS) in order to keep the plots free of weeds at all times.

\section{Data Collection and analysis}

In each of the experimental plots of $4 \mathrm{~m} \times 4 \mathrm{~m}\left(16 \mathrm{~m}^{2}\right)$, a $0.5 \mathrm{~m}-.05 \mathrm{~m}$ was removed to eliminate border effect, leaving a net plot of $3.5 \mathrm{~m} \times 3.5 \mathrm{~m}\left(12.25 \mathrm{~m}^{2}\right)$. A sample area $\left(\mathrm{m}^{2}\right)$ was taken using quadrat drill calibrated in $1 \mathrm{~m} \times 1 \mathrm{~m}$. Quadrat drill is one of the many sampling tools commonly used to collect data in the field. It helps restrict the exercise within the quadrat and plants used for sampling were randomly selected from within it. Inside the $1 \mathrm{~m} \times 1 \mathrm{~m}$ quadrat, the planting geometry of $15 \mathrm{~cm} \mathrm{x} 15 \mathrm{~cm}, 20 \mathrm{~cm} \times 20 \mathrm{~cm}$, and $25 \mathrm{~cm} \times 25 \mathrm{~cm}$ gave 44 plants, 25 plants and 16 plants respectively from which ten (10) plants (hills) were randomly selected for tagging. Tagging was done using red ribbon which can easily be visible. All the data for growth and yield characters however, were taken only at maturity (harvest). All data taken were imputed into MS excel and SPSS version 22 package and subjected to statistical analysis of variance (ANOVA) while significant difference among treatment means were separated using the Duncan Multiple Range Test (DMRT) following the procedure of Duncan (1955).

\section{RESULTS AND DISCUSSIONS}

\subsection{Plant Height (cm)}

Table 1 shows that age of seedlings, row spacing and cropping season had significant effects on plant height $(\mathrm{P} \leq 0.05)$. Seedlings transplanted at 17 -day old had taller plants $(69.05 \mathrm{~cm})$, followed by seedlings transplanted at 19 -day old $(68.24 \mathrm{~cm}$. There was no difference in plant height between 15 - and 35 -days seedlings $(66.67 \mathrm{~cm})$ and $(66.61 \mathrm{~cm})$ respectively; in contrast the direct seeded crops had the least plant height $(65.63 \mathrm{~cm})$. The significantly taller plants among the different seedling ages, indicates the importance of seedling age in transplanting of rice. The increase in plant height observed with younger seedlings could be due to less root damage during uprooting, as their root length is shorter and less established compared to the 35 days old seedlings and direct seeded crops. Transplanting shock with younger seedlings is minimal compared to older seedlings and direct seeded crops. This result is in agreement with the findings of Durga et al. (2015) who found out that plant height at maturity better reaches its maximum when the crop was transplanted at 14-days after emergence. 
Row spacing of $20 \times 20 \mathrm{~cm}$ produced taller plants which were at par with that of $25 \times 25 \mathrm{~cm}$. Row spacing of $15 \times 15 \mathrm{~cm}$ on the other hand, had the least plant height. Taller plants with wider spacing compared to closer spacing showed that more nutrients are available to individual crop for establishment and continuous growth while at closer spacing, competition sets in and growth is retarded, Kumal et, al (1998) and Singh et al (2002) obtained similar results and therefore attributed taller plants with optimum seedling density and wider spacing

Growing rice during the wet season produced taller plants $(75.75 \mathrm{~cm})$, in contrast shorter crops were produced when the crop was grown during the dry season $(58.72 \mathrm{~cm})$. This shows that rice being a water loving plant, grow faster in the wet season than during the dry season, shorter plants observed during the dry season could be as a result of the regulation of irrigation water applied during the experiment. These findings are in conformity with the reports of Shimono et al. (2007) who observed that adequate water supply leads to taller plants

\subsection{Number of tillers/hill}

Age of transplanting, row spacing and cropping season had significant effects $(\mathrm{P} \leq 0.05)$ on the number of tillers/hill. More tillers (70.75) were produced by 19 day old seedlings followed by 17-day old transplanted seedlings (69.46). Seedlings transplanted on day 15 and 35 as well as the direct seeded had fewer tillers at 68.51, 68.81, and 68.77 respectively. Higher number of tillers observed when seedlings were transplanted at a young age with barely 2 leaves shows the importance of seedling age in tillering of rice plant. However, the result further revealed that the seedlings to be transplanted should not be very young as less than 19 day old. Therefore, when younger seedlings are transplanted, it results in more productive tillers. However, when the seedlings are too young, for example 15 days after sowing in the nursery, they result in less number of tillers and this could be because the seedlings are too tender/delicate and when uprooted for transplanting they suffer transplanting shock and root damage. This observation corroborates the result of an earlier study carried out by Uphoff et al. (2003), who concluded that when seedlings are uprooted at 10 days after emergence, they produce fewer tillers compared to 14 days after emergence. Seedlings transplanted at $25 \times 25 \mathrm{~cm}$ inter and intra row spacing consistently had higher number of tillers (71.96), followed by seedlings transplanted at row spacing of $20 \times 20 \mathrm{~cm}$ (68.86). Seedlings transplanted/sown at $15 \times 15 \mathrm{~cm}$ had fewer tillers (67.00). The higher number of tillers observed under $25 \times 25 \mathrm{~cm}$ spacing could be an indication that all the plants at such spacing, had all the required mineral resources at their disposal to grow and produce more tillers without much competition. The present result agrees with an earlier study by Balasubramanian and Palaniappan (1991) that attributed higher number of tillers to more space for individual plants to put forth more tillers. Dry season rice produced higher number of tillers (73.43) than the wet season cropping (65.08). There was more solar radiation during the dry season which promoted higher photosynthesis. This result is corroborated by an earlier study by Yoshida, (1973), and a more recent report by Sridevi and Chellamuthu (2015), that higher tiller number could be obtained under dry season cropping. 
International Journal of Agriculture, Environment and Bioresearch

Vol. 5, No. 01; 2020

ISSN: $2456-8643$

Table 1: Effect of seedling age, row spacing and cropping season on plant height and number of tillers/hill of rice taken at harvest.

Plant height (cm) Number of tillers/hill

Treatments

Seedling Age (days)

15

$66.67 \mathrm{c}$

$68.51 \mathrm{c}$

17

$69.05 \mathrm{a}$

$69.46 \mathrm{~b}$

19

$68.24 \mathrm{~b}$

$70.75 \mathrm{a}$

35

$66.61 \mathrm{c}$

$68.81 \mathrm{c}$

DS(Control)

$65.63 \mathrm{~d}$

$68.77 \mathrm{c}$

LS

$*$

*

SE $( \pm)$

0.703

0.491

Row Spacing (cm)

$15 \times 15$

$66.24 \mathrm{~b}$

$67.00 \mathrm{c}$

20x20

$68.19 \mathrm{a}$

$68.86 \mathrm{~b}$

$25 \times 25$

$67.29 \mathrm{a}$

$71.96 \mathrm{a}$

LS

*

SE ( \pm$)$

0.545

0.380

Season

Dry

$58.72 b$

$73.43 a$

Wet

$75.75 \mathrm{a}$

$65.08 \mathrm{~b}$

LS

*

*

SE $( \pm)$

0.445

0.310 
Vol. 5, No. 01; 2020

ISSN: $2456-8643$

Means followed by same letter (s) in the same column do not differ significantly following Duncan Multiple Range Test (DMRT) LS= Level of Significant. *= Significant at 5\% level of probability.

\subsection{Panicle length}

Table 2 shows that age of seedlings, row spacing and cropping season had significant effects $(\mathrm{P} \leq 0.05)$ on panicle length. The 35 day old transplants and direct seeded crops produced longer panicles while 19-day old transplanted seedlings recorded shorter panicles. This could be due to less number of tillers that were produced by the direct seeded and the 35 day old seedlings. The direct seeded took about 10 days to emerge to the surface, while the 35 day old transplanted seedlings may have suffered root damage during uprooting, both reasons could result in delay of establishment of the seedlings in the field and thus affect panicle length. When fewer tillers are produced there is less competition among the individual tillers hence the resulting panicles grow longer but they may produce fewer grains compared to 19 day old seedlings with more tillers and spikelets per panicle. This finding is in conformity with the results obtained by Mondal et al. (2013), who concluded in an earlier study that when tillers are few, they experience less competition and therefore produce longer panicles, but that the final grain yield will be influenced more by the number of tillers than by the length of the panicle. At the different row, $25 \times 25 \mathrm{~cm}$ produced longer panicles, followed by row spacing of $20 \times 20 \mathrm{~cm}$ while row spacing of $15 \times 15 \mathrm{~cm}$ had shorter panicles. This could be due to lack of competition for sunlight and nutrients between the widely spaced plants, while the densely spaced plants tend to undergo intense competition which then resulted in shorter panicles. Similar trends were reported by Mahmood et al. (2002) who noted that rice transplanted at wider spacing of $20 \times 15 \mathrm{~cm}$ or $30 \times 15 \mathrm{~cm}$ recorded significantly longer panicles than at closer spacing of $15 \times 15 \mathrm{~cm}$. Longer panicles produced when older seedlings ( 35 day old) were transplanted during the dry season, could be due to few number of tillers produced by the older seedlings which gave rise to minimal competition for nutrients and sunlight. Similar results were reported by Sarker et al. (2002) who observed that transplanting older seedlings could result in longer panicles due to less number of tillers.

\subsection{Number of panicles/hill}

Age of transplanting, row spacing and cropping season had significant effects $(\mathrm{P} \leq 0.05)$ on number of panicles/hill. The 19 day old transplanted seedlings produced higher number of panicles followed by 17-day old seedlings. There was no difference in number of panicles between the 15, 35 day old seedlings and the direct seeded crops. This result indicates that transplanting younger seedlings might have increased the number of panicles produced per hill. This could be that when seedlings are transplanted early, they experience minimal transplanting shock. On the other hand, 35 day old seedling had less number of panicles per hill this could be that when seedlings remained longer in the nursery, the transplanting shock is more severe. Direct sown plants had the least number of panicles per hill, which could be due to the fact that nutrients in the endosperm were utilized to promote growth through the top soil. The findings of this study is supported by the earlier results of Sarker et al. (2002) and Akbar (2004) who noted that when rice seedlings are transplanted early the crop experienced minimal transplanting shock which then help the crop to put out more tillers and eventually more panicles. It was also pointed 
out that when 30-day old seedlings are transplanted they developed less number of panicles which could be as a result of transplanting shock. Row spacing of $25 \times 25 \mathrm{~cm}$ produced more panicles, followed by row spacing of $20 \times 20 \mathrm{~cm}$, while row spacing of $15 \times 15 \mathrm{~cm}$ had the least number of panicles. This could be because of enough space provided which led to less competition for nutrients in the soil between seedlings. Similarly, wider spacing affords the plant leaves more area for solar radiation interception, thereby resulting in higher rate of photosynthesis, which ultimately increases panicle formation. The result of the study is in conformity with the findings of Biradir (2009) who stated that planting in square method at wider spacing of $25 \times 25 \mathrm{~cm}$ resulted in profuse tillering under SRI cultivation which might have facilitated plants for better utilization of resources, therefore leading to the production of more panicles/hill.

\subsection{Panicle weight $(\mathrm{g})$}

The significant effect $(\mathrm{P} \leq 0.05)$ of seedling age, row spacing and cropping season on panicle weight shows that 19 day old transplanted seedlings produced heavier panicles, followed by seedlings transplanted on day 17. The direct seeded crops and 35 days old produced the least panicle weight. This result shows that when seedlings are transplanted early, they tend to absorb enough moisture from the soil to carry out their photosynthetic activities, therefore the accumulation of carbohydrate in the panicles tend to increase the weight of the panicles. Lighter panicle as a result of transplanting older seedlings (35 days old), which was at par with direct seeded crops, could be due to poor grain filling leading to lower panicle weight. This result corroborates the work of Alam (2006) who recorded heavier panicles under 18-day old seedlings and lighter panicles when 12 days old seedlings were transplanted. The different row spacing showed that the $25 \times 25 \mathrm{~cm}$ seedlings produced heavier panicles, followed by seedlings transplanted at row spacing of $20 \times 20 \mathrm{~cm} ; 15 \times 15 \mathrm{~cm}$ had the least panicle weight. This could be because wider spacing enables the seedlings to develop more roots due to lack of competition between the plants. Also with enough nutrients and available sunlight, more carbohydrate is produced leading to more grain filling and thus heavy panicles. Similar views were also expressed by Alam (2006) who noted that panicle weight varied with various planting geometry with maximum weight obtained under $25 \times 25 \mathrm{~cm}$ spacing.

Table 2: Effect of seedling age, row spacing and cropping season on panicle length, number of panicles/hill and panicle weight of rice taken at harvest

\section{Panicle length(cm) Number of panicles/hill panicle weight (g)}

\section{Treatments}

Seedling Age (days)

15

$21.59 \mathrm{~d}$

$33.94 \mathrm{c}$

$28.58 b$ 


\begin{tabular}{|lccc|}
\hline 17 & $21.72 \mathrm{~b}$ & $34.93 \mathrm{~b}$ & $28.46 \mathrm{~b}$ \\
19 & $21.69 \mathrm{c}$ & $35.33 \mathrm{a}$ & $28.79 \mathrm{a}$ \\
35 & $22.21 \mathrm{a}$ & $33.93 \mathrm{c}$ & $27.46 \mathrm{c}$ \\
DS(Control) & $22.16 \mathrm{a}$ & $33.66 \mathrm{c}$ & $27.68 \mathrm{c}$ \\
LS & $*$ & $*$ & $*$ \\
SE $( \pm)$ & 0.103 & 0.372 & 0.273 \\
Row Spacing (cm) & & & \\
$15 \times 15$ & $21.70 \mathrm{c}$ & $32.40 \mathrm{c}$ & $26.13 \mathrm{c}$ \\
$20 \times 20$ & $21.90 \mathrm{~b}$ & $35.06 \mathrm{~b}$ & $27.77 \mathrm{~b}$ \\
$25 \times 25$ & $22.02 \mathrm{a}$ & $36.52 \mathrm{a}$ & $30.71 \mathrm{a}$ \\
LS & $*$ & $*$ & $*$ \\
SE $( \pm)$ & 0.079 & 0.288 & 0.212 \\
Season & & & \\
Dry & 21.81 & 34.89 & $25.89 \mathrm{~b}$ \\
Wet & 21.94 & 34.42 & $30.51 \mathrm{a}$ \\
LS & NS & NS & $*$ \\
SE $( \pm)$ & 0.065 & 0.235 & 0.173 \\
& & & \\
\hline
\end{tabular}

Means followed by same letter (s) in the same column do not differ significantly following Duncan Multiple Range Test (DMRT).LS= Level of Significant. *= Significant at 5\% level of probability. NS = Not Significant

\subsection{Number of spikelet/panicle}

Table 3 shows a significant effect $(\mathrm{P} \leq 0.05)$ of seedling age, row spacing and cropping season on number of spikelets/panicle. More spikelets were observed with the 19 day old transplanted seedlings, followed by 17-day old transplanted seedlings. On the other hand, fewer spikelets were produced by seedlings transplanted on day 15 and 35 as well as the direct seeded crop. This result indicates that transplanting young seedlings under good cultural practices and weather conditions could lead to the production of higher yield characters like spikelets. Transplanting 
younger seedlings before the fourth phyllochron tend to experience minimal transplanting shock, which might have given rise to more tillers, which subsequently led to the production of more spikelets per panicles. Similar results were reported by Durga et al. (2015), who observed that when seedlings are transplanted early before the fourth phyllochron, they tend to suffer minimal transplanting shock and as a result they quickly establish in the field. Row spacing of $25 \times 25 \mathrm{~cm}$ had higher number of spikelets/panicle, while $15 \times 15 \mathrm{~cm}$ had the least number of spikelets/panicle. This could be due to minimal competition for nutrients as well as efficient use of available resources for photosynthesis. This result agrees with the earlier results of Hay and Walker (1989) who observed that increase in plant population as a result of closer row spacing may lead to increase inter plant competition which may subsequently affect yield and yield components. The wet season crop had more spikelets/panicle than dry season crop. This could be due to the fact that rice is a water loving plant, however high soil moisture content especially during the reproductive stage could lead to spikelet sterility. Similar results were obtained by Hay and Walker (1989), and therefore concluded that spikelet sterility usually occurs when there is too much soil moisture content during the reproductive stage.

\subsection{One thousand seed weight (g)}

Age of seedlings, row spacing and cropping season showed significant $(\mathrm{P} \leq 0.05)$ variation on one thousand seed weight. The 17 and 19-day old seedlings produced heavier seeds, compared to the other treatment combinations. This result showed that there was better grain filling of younger transplants than the older ones. When seedlings are transplanted early with minimal transplanting shock, they tend to establish better with healthy and heavier grains, this present report lend support for the results of Paul et al. (2016), who reported that when seedlings are transplanted early, they experience better performance both in growth and yield characters leading to better grain filling and thus heavier seeds. Inter and intra row spacing of $25 \times 25 \mathrm{~cm}$ produced higher seed weight than the other row spacing used, while transplanting at $15 \times 15 \mathrm{~cm}$ consistently had the least seed weight. This result indicates that there is better utilization of mineral resources and sunlight for photosynthesis when seedlings are transplanted at such distance. These findings agree with that of Banison (2002), who noted that seedlings spaced $25 \times 25 \mathrm{~cm}$ had higher 1000 seed weight due to minimal competition among them with better grain filling. Considering the two seasons under investigation, there was a significantly $(\mathrm{P} \leq 0.05)$ higher seed weight observed with the crop grown during the dry season compared to when the crop was cultivated during the wet season. This could be attributed to favorable conditions like high intensity of light and efficient water management which probably led to higher availability and translocation of nutrients during growth and development stage of the crop. The decrease in one thousand seed weight recorded during the wet season may also relate to low sunshine hours like the cloudy days as earlier reported by Benitos (1992).

\subsection{Grain yield (t/ha)}

Grain yield of rice as influenced by seedling age, row spacing and cropping season showed that there was a significant $(\mathrm{P} \leq 0.05)$ variation among all the treatments, the 19-day old transplanted seedlings consistently had higher grain yield than the rest of the treatments applied. This was followed by 17-day old seedlings, while 15-day old transplanted seedlings produced the least 
grain yield, which was at par with the 35-day old transplanted seedlings and the direct seeded plots. Increase in grain yield with younger seedlings compared to 35 day old and direct seeded crops, shows the importance of transplanting young seedlings rather than aged ones and transplanting rice rather than direct seeding in the field. The reason could be that at younger age the transplanting shock is minimal because the root is shallow, unlike older seedlings that are deeply rooted and could therefore suffer root damage and more intense transplanting shock. These findings are in conformity with the findings of Uphoff (2003) and Zhang et al. (2004) and the recent report of Durga et al (2015) that higher grain yield was obtained when 12 and 14 days old seedlings were transplanted. At the different row spacing, it was observed that row spacing of $25 \times 25 \mathrm{~cm}$ produced significantly $(\mathrm{P} \leq 0.05)$ higher grain yield followed by seedlings transplanted at row spacing of $20 \times 20 \mathrm{~cm}$. Seedlings transplanted at the row spacing of $15 \times 15 \mathrm{~cm}$ however, had the least grain yield per hectare. This shows that with minimal competition between the plants for mineral resources, and probably better ability of the plant leaves to utilize the energy from the sun for photosynthesis and translocation of assimilates, yields are bound to increase significantly. These findings corroborates reports of several other researchers e.g. Uphoff et al. (2003), Luikham (2008) and Thawait et al. (2014), who concluded that higher grain yields were obtained at wider rice spacing e.g $25 \times 25 \mathrm{~cm}$ compared to narrow spacing of $15 \times 15 \mathrm{~cm}$. Between the two seasons, significant difference was also observed. The dry season crop production, resulted in higher grain yield than the wet season production, this could be due to better water management, optimum conditions for light interception, aerating the soil using cono weeder, soil being kept moist rather than flooded and planting one seedling per hill as recommended by SRI. During the dry season, there was higher intensity of solar radiation, and therefore, with good water management, photosynthetic activities will equally be high and more translocation of carbohydrates for grain formation and filling as well as other yield components of rice will be increased. Similar observations were made by De-Datta (1981) while studying the effect of solar radiation between flowering and ripening on grain yield of rice 
Table 3: Effect of seedling age, row spacing and cropping season on spikelet/panicle, 1000 seed weight and grain yield of rice taken at harvest

\begin{tabular}{|c|c|c|c|}
\hline \multicolumn{2}{|l|}{ Treatments } & & \\
\hline \multicolumn{4}{|l|}{ Seedling Age (days) } \\
\hline 15 & $154.96 \mathrm{c}$ & $22.68 b$ & $3.57 \mathrm{c}$ \\
\hline 17 & $170.32 b$ & $24.08 \mathrm{a}$ & $4.38 b$ \\
\hline 19 & $180.25 \mathrm{a}$ & $24.00 \mathrm{a}$ & $5.28 \mathrm{a}$ \\
\hline 35 & $154.87 \mathrm{c}$ & $22.62 b$ & $3.33 \mathrm{c}$ \\
\hline DS(Control) & $156.57 \mathrm{c}$ & $22.76 b$ & $3.14 \mathrm{c}$ \\
\hline LS & $*$ & $*$ & $*$ \\
\hline $\operatorname{SE}( \pm)$ & 4.668 & 0.400 & 0.070 \\
\hline \multicolumn{4}{|l|}{ Row Spacing (cm) } \\
\hline $15 \times 15$ & $139.44 \mathrm{c}$ & $21.63 c$ & $4.27 \mathrm{~b}$ \\
\hline $20 \times 20$ & $158.79 b$ & $22.63 b$ & $4.50 \mathrm{~b}$ \\
\hline $25 \times 25$ & $191.95 \mathrm{a}$ & $24.42 \mathrm{a}$ & $5.29 \mathrm{a}$ \\
\hline LS & $*$ & $*$ & $*$ \\
\hline $\mathrm{SE}( \pm)$ & 3.615 & 0.310 & 0.054 \\
\hline \multicolumn{4}{|l|}{ Season } \\
\hline Dry & $128.75 b$ & $24.11 \mathrm{a}$ & $6.04 \mathrm{a}$ \\
\hline Wet & $198.04 \mathrm{a}$ & $23.37 \mathrm{~b}$ & $4.12 b$ \\
\hline LS & $*$ & $*$ & $*$ \\
\hline $\mathrm{SE}( \pm)$ & 2.952 & 0.253 & 0.044 \\
\hline
\end{tabular}


Means followed by same letter (s) in the same column do not differ significantly following Duncan Multiple Range Test (DMRT) LS= Level of Significant. *= Significant at 5\% level of probability

\section{CONCLUSION AND RECOMMENDATIONS}

Based on the results obtained from the study it can be concluded that transplanting of rice at 19 days after sowing in the nursery and at a spacing of $25 \times 25 \mathrm{~cm}$ during the dry season, increased the grain yield.

Therefore based on the findings the farmers in the study area are advised to i) raise seedlings in the nursery and later transplant at the age of 19 days after sowing in the nursery, ii) during transplanting farmers should space the seedlings as wide as $25 \times 25 \mathrm{~cm}$ for optimum rice production, iii) dry season should be practiced for all year round rice production and higher yield of the crop.

\section{REFERENCES}

Alam, F (2006), Effect of spacing, number of seedlings per hill and fertilizer management on performance ofBoro rice CV. BRRI dhan29. M.S Thesis, department of

Agronomy,Bangladesh Agriculture University, Mymensingh. Pp 24-27

Akbar, M.K (2004), A study of hybrid and inbred varieties to different seedling ages under the system of rice intensification in transplant aman season. M.S Thesis.Department of Agronomy. Bangladesh Agriculture University. Mymensingh Pp 59

Balasubramanian, P. \& Palaniappan, S.P. (1991). Effect of high-density population and

fertilizer rate on growth and yield of lowland rice. Indian Journal of Agronomy. 3(1):10-13

Banison, J (2002), Evaluation of nutrient uptake and nutrient use efficiency of SRI conventional rice cultivation methods in Madagascar. In:

Proceedings of International Conference on Assessments of System of Rice Intensification. Sanya, China. April 1-4, 2002

Benitos, S.V (1992), A farmer's primer on growing rice. International Rice Research Institute (IRRI). Manila, Phillipine, 215Pp

Biradir, P.N.K (2009), Studies on seed production techniques and storability of Kamataka rice hybrid-2. Ph.D Thesis. University of Agricultural Sciences. Dharwad. India

De-Datta, S.K (1981), Principles and practices of rice production. In: Climate effect on rice production, John Wiley and Sons, Singapore. 18-440PP 
Duncan, B. D. (1955). Multiple Range and Multiple F Test. Biometrics 11: 1-42

Durga, K. K., Sambasiva, R. O and Raju, K. (2015). Effect of seedling age and spacing schedule on the productivity and quality traits of ric under System os Rice Intensification (SRI). Journal of Cereals and Oilseeds. 6(3):15-19

Food and Agriculture Organization, FAO. (2015). Food and Agricultural Organization of the United Nations, Statistics Division, Rome

Food and Agriculture Organization, FAO. (2017). Food and Agricultural Organization of the United Nations, Statistics Division, Rome

Hay, R. K and Walker, J. A. (1989). An introduction to the physiology of crp yirld. Longman Scientific Technical P. 167

Johnson, B., \& Mellor J (1961). The role of agriculture in economicdevelopment. Am. Econ. Rev. 51(4), 566-593.

Kumar, A., Singh, D.P. and Yadav, S.K. (1998).Partitioning of dry matter accumulation in aestivum and durum wheat under irrigated andnon-irrigated field conditions. Indian Journal of Plant Physiology, 30: 126-129.

Luikham, E., Yamtong, K. and Mariam Anal, P. S. 2008. Effect ofplanting geometry

and nitrogen levels on productivity of black aromatic rice (oryza sativa 1.) under rainfed conditions. Agricultural. Science. Digest. 28(2): 153-154.

Mahmood , N., Chatha, Z.A., Akhtak, B \& Saleem M. (2002). Response of rice to different sowing methods. Asian journal of plant sciences 1(2):144-145

Mensah,1989: "Argentina's economic reforms expand growth potential for agriculture." Agricultural Outlook Pp 24-30

Mondal M.M.A, Putch A.B. (2013).Optimizing plant spacing for modern rice varieties. International Journal of Agriculture and Biology.15:175-178

Paul Reuben, Zachariah Katambara, Fredrick C. Kahimba, Henry F. Mahoo, et al

(2016). Influence of transplanting age on paddy yield under system of rice intensification. Agricultural Sciences,7, 154-163. Published online March 2016 in SciRes. http://www.scirp.org/journal.as

Pretty, P.L (1995), Vietnam: decollectivization and rice productivity growth.

Economics Development and Cultural Change 40(4), pp. 697-718

Sarker, G., Rahman, M., Hasan, R., \& Roy S.C (2002). SRI, yield and economic potential in Boro rice at different locations of Bangladesh. LIFE NOPEST Project, CARE- Bangladesh. Pp $1-5$ 
Shimono, H., Okada, H., Kanda. E., Arakawa, I., (2007): Low temperature induced sterility in rice: evidence for the effects of temperature before panicle initiation. Field Crops Research. 101:221-231

Singh, A.K., B.U Choudhurry, and B.A.M Bouman (2002). Effects of rice establishment methods on crop performance, water use and mineral nitrogen. In: Water-wise rice production. Proceedings of a thematic workshop on Water-wise rice production, 8-11 April 2002 at IRRI Headquarters in Los Banos; Phillipines. Pp76-89

Sridevi, V. and Challamuthu. V. (2015). A review on impact of weather on rice. International Journal of Applied Research. 1(9):825-831

Thawait, D., Patel, A. K., Kar, S., Sharma, M. K. and Meshram, M. R.2014. Performance of transplanted scented rice (Oryza sativa L.) undersri based cultivation practices; a sustainable method for cropproduction. The Bioscan. 9(2): 539-542

Timberlake,N.C (1990), Market reform, incentives and economic development in Vietnamese rice production. Comparative EconomicStudies 48(2), pp. 277-301.

Uphoff, N (2003) Higher yields with fewer external inputs. The system of rice intensification and potential contributions to agricultural sustainability. Journal of Agricultural Research and Management, 1(1):21-28

USAID (2010): Rice Investment and Processing in Nigeria

Yoshida, S (1973), Effect of temperature on the growth of rice plant (Oryza sativa L) in

controlled environment. Journal of Soil Science and Plant Nutrition. 19(4):299-31 